\title{
Solving Cauchy reaction-diffusion equation by using Picard method
}

\author{
Shadan Sadigh Behzadi
}

\begin{abstract}
In this paper, Picard method is proposed to solve the Cauchy reaction-diffusion equation with fuzzy initial condition under generalized $\mathrm{H}$-differentiability. The existence and uniqueness of the solution and convergence of the proposed method are proved in details. Some examples are investigated to verify convergence results and to illustrate the efficiently of the method. Also, we obtain the switching points in examples.
\end{abstract}

Keywords: Cauchy reaction-diffusion equation; Fuzzy number; Fuzzy-valued function; $h$-difference; Generalized differentiability; Picard method

\section{Introduction}

As we know the fuzzy differential equations $F D E$ are one of the important part of the fuzzy analysis theory that play major role in numerical analysis. For example, population models (Guo et al. 2003), the golden mean (Datta 2003), quantum optics and gravity (El Naschie 2005), control chaotic systems (Feng and Chen 2005; Jiang 2005), medicine (Abbod et al. 2001; Barro and Marin, 2002). Recently, some mathematicians have studied FDE (Abbasbandy and Allahviranloo 2000; Abbasbandy et al. 2004; Abbasbandy et al. 2005; Allahviranloo et al. 2007; Bede 2008; Bede and Gal 2005; Bede et al. 2007; Buckley and Feuring 2000; Buckley and Jowers 2006; Buckley et al. 2002; Chalco-Cano and Romn-Flores 2006; ChalcoCano and Romn-Flores et al. 2007; Chapko and Johansson 2012; Chen and Ho 1999; Cho and Lan 2007; Congxin and Shiji 1993; Diamond 1999; Diamond 2002; Ding et al. 1997; Dubois 1982; Dou and Hon 2012; Fard 2009a,b; Fard and Bidgoli 2010; Fard and Kamyad 2011; Fard et al. 2009; Fei 2007; Jang et al. 2000; Jowers et al. 2007; Kaleva 1987,1990,2006; Lopez 2008; Ma et al. 1999; Mizukoshi et al. 2007; Oberguggenberger and Pittschmann 1999; Papaschinopoulos 2007; Puri and Ralescu 1983; Seikkala 1987; Solaymani Fard and Ghal-Eh 2011; Song et al. 2000). The fuzzy partial differential equations FPDE are very important in mathematical models of physical, chemical,

Correspondence: shadan_behzadi@yahoo.com

Department of Mathematics, Science and Research Branch, Islamic Azad University, Tehran, Iran biological, economics and other fields. Some mathematicians have studied solution of FPDE by numerical methods (Afshar Kermani and Saburi 2007; Allahviranloo 2002; Barkhordari Ahmadi and Kiani 2011; Buckley and Feuring 1999; Chen et al. 2009; Farajzadeh et al. 2010; Moghadam and Jalal 2011; Rouhparvar et al. 2010; Verma et al. 2009). In this work, we present the Picard method to solve the Cauchy reaction-diffusion equation as follows:

$$
\begin{array}{ll}
\tilde{u}_{t}(x, t)=\widetilde{u}_{x x}(x, t)+\widetilde{u}(x, t), & 0 \leq t \leq T, \\
& a \leq x \leq b, a, b, T \in R .
\end{array}
$$

With fuzzy initial condition:

$$
\widetilde{u}(x, 0)=\tilde{f}(x) \text {. }
$$

The structure of this paper is organized as follows: In section "Basic concepts", some basic notations and definitions in fuzzy calculus are brought. In section "Description of the method", Eqs. $(1,2)$ are solved by Picard method. The existence and uniqueness of the solution and convergence of the proposed method are proved in section "Existence and convergence analysis" respectively. Finally, in section "Numerical examples", the accuracy of method by solving some numerical examples are illustrated and a brief conclusion is given in section "Conclusion".

\section{Basic concepts}

Here basic definitions of a fuzzy number are given as follows, (Allahviramloo 2005; Dubois and Prade 2005; Kauffman and Gupta 1991; Nguyen 1978; Zadeh 1965)

\section{Springer}

(c) 2013 Sadigh Behzadi; licensee Springer. This is an Open Access article distributed under the terms of the Creative Commons Attribution License (http://creativecommons.org/licenses/by/2.0), which permits unrestricted use, distribution, and reproduction in any medium, provided the original work is properly cited. 


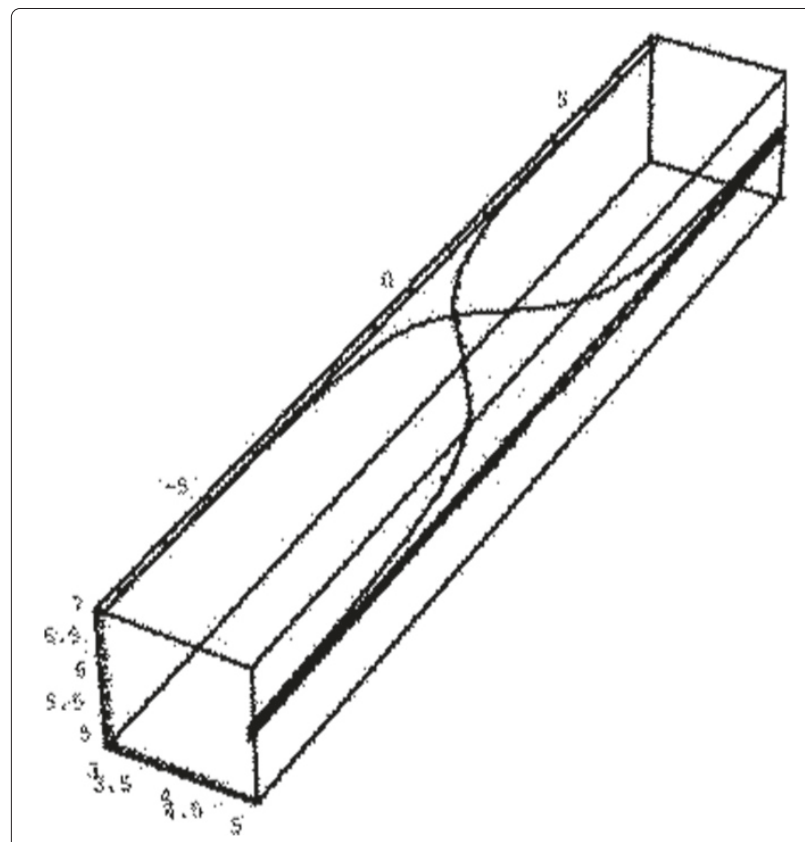

Figure 1 The results of Example 5.1 for $(\underline{u}(x, 0.6,0.1), \bar{u}(x, 0.6,0.1))$.

Definition 2.1. An arbitrary fuzzy number $\widetilde{u}$ in the parametric form is represented by an ordered pair of functions $(\underline{u}, \bar{u})$ which satisfy the following requirements:

(i) $\bar{u}: r \rightarrow \underline{u}(r) \in R$ is a bounded left-continuous non-decreasing function over $[0,1]$,

(ii) $\underline{u}: r \rightarrow \bar{u}(r) \in R$ is a bounded left-continuous non-increasing function over $[0,1]$,

(iii) $\underline{u}(r) \leq \bar{u}(r), \quad 0 \leq r \leq 1$.

Definition 2.2. For arbitrary fuzzy numbers $\tilde{u}, \tilde{v} \in E^{1}$, we use the distance (Hausdorff metric) (Goetschel and Voxman 1986) $D(u(r), v(r))=\max \left\{\sup _{r \in[0,1]} \mid \underline{u}(r)-\right.$ $\underline{v}(r) \mid$, sup $|\bar{u}(r)-\bar{v}(r)|\}$, and it is shown (Puri and Ralescu $1986)$ that $\left(E^{1}, D\right)$ is a complete metric space and the following properties are well known:

$D(\widetilde{u}+\widetilde{w}, \widetilde{v}+\widetilde{w})=D(\widetilde{u}, \widetilde{v}), \forall \widetilde{u}, \widetilde{v} \in E^{1}$,

$D(k \widetilde{u}, k \widetilde{v})=|k| D(\widetilde{u}, \widetilde{v}), \forall k \in R, \widetilde{u}, \widetilde{v} \in E^{1}$,

$D(\widetilde{u}+\widetilde{v}, \widetilde{w}+\widetilde{e}) \leq D(\widetilde{u}, \widetilde{w})+D(\widetilde{v}, \widetilde{e}), \forall \widetilde{u}, \widetilde{v}, \widetilde{w}, \widetilde{e} \in E^{1}$.

Definition 2.3. Consider $\widetilde{x}, \tilde{y} \in E$. If there exists $\widetilde{z} \in E$ such that $\tilde{x}=\tilde{y}+\widetilde{z}$ then $\widetilde{z}$ is called the $H$-difference of $\tilde{x}$ and $\tilde{y}$, and is denoted by $\tilde{x} \ominus \tilde{y}$ (Bede and Gal 2005).

Proposition 1. If $\tilde{f}:(a, b) \rightarrow E$ is a continuous fuzzyvalued function then $g(x)=\int_{a}^{x} f(t) d t$ is differentiable, with derivative $g^{\prime}(x)=f(x)$ (Bede and Gal 2005).
Definition 2.4. (see (Bede and Gal 2005)) Let $\tilde{f}:(a, b) \rightarrow$ $E$ and $x_{0} \in(a, b)$. We say that $\widetilde{f}$ is generalized differentiable at $x_{0}$ (Bede-Gal differentiability), if there exists an element $f^{\prime}\left(x_{0}\right) \in E$, such that:

i) for all $h>0$ sufficiently small, $\exists f\left(x_{0}+h\right) \ominus f\left(x_{0}\right)$, $\exists f\left(x_{0}\right) \ominus f\left(x_{0}-h\right)$ and the following limits hold:

$$
\begin{aligned}
\lim _{h \rightarrow 0} \frac{f\left(x_{0}+h\right) \ominus f\left(x_{0}\right)}{h} & =\lim _{h \rightarrow 0} \frac{f\left(x_{0}\right) \ominus f\left(x_{0}-h\right)}{h} \\
& =f^{\prime}\left(x_{0}\right)
\end{aligned}
$$

or

ii) for all $h>0$ sufficiently small, $\exists f\left(x_{0}\right) \ominus f\left(x_{0}+h\right)$, $\exists f\left(x_{0}-h\right) \ominus f\left(x_{0}\right)$ and the following limits hold:

$$
\begin{aligned}
\lim _{h \rightarrow 0} \frac{f\left(x_{0}\right) \ominus f\left(x_{0}+h\right)}{-h} & =\lim _{h \rightarrow 0} \frac{f\left(x_{0}-h\right) \ominus f\left(x_{0}\right)}{-h} \\
& =f^{\prime}\left(x_{0}\right)
\end{aligned}
$$

or

iii) for all $h>0$ sufficiently small, $\exists f\left(x_{0}+h\right) \ominus f\left(x_{0}\right)$, $\exists f\left(x_{0}-h\right) \ominus f\left(x_{0}\right)$ and the following limits hold:

$$
\begin{aligned}
\lim _{h \rightarrow 0} \frac{f\left(x_{0}+h\right) \ominus f\left(x_{0}\right)}{h} & =\lim _{h \rightarrow 0} \frac{f\left(x_{0}-h\right) \ominus f\left(x_{0}\right)}{-h} \\
& =f^{\prime}\left(x_{0}\right)
\end{aligned}
$$

or

iv) for all $h>0$ sufficiently small, $\exists f\left(x_{0}\right) \ominus f\left(x_{0}+h\right)$, $\exists f\left(x_{0}\right) \ominus f\left(x_{0}-h\right)$ and the following limits hold:

$$
\begin{aligned}
\lim _{h \rightarrow 0} \frac{f\left(x_{0}\right) \ominus f\left(x_{0}+h\right)}{-h} & =\lim _{h \rightarrow 0} \frac{f\left(x_{0}\right) \ominus f\left(x_{0}-h\right)}{h} \\
& =f^{\prime}\left(x_{0}\right)
\end{aligned}
$$

Definition 2.5. Let $\tilde{f}:(a, b) \rightarrow E$. We say $\tilde{f}$ is (i)differentiable on $(a, b)$ if $\tilde{f}$ is differentiable in the sense (i) of Definition (2.7) and similarly for (ii), (iii) and (iv) differentiability.

Definition 2.6. (see (Chalco-Cano and Romn-Flores 2006)) Let $\widetilde{f}:(a, b) \rightarrow E$ and $x_{0} \in(a, b)$. A point $x_{0} \in(a, b)$ is said to be a switching point for the differentiability of $\widetilde{f}$, if in any neighborhood $V$ of $x_{0}$ there exist points $x_{1}<x_{0}<x_{2}$ such that

(type 1) $\tilde{f}$ is differentiable at $x_{1}$ in the sense $(i)$ of Definition (2.6) while it is not differentiable in the sense (ii) of Definition (2.6), and $\widetilde{f}$ is differentiable at $x_{2}$ in the sense (ii) of Definition (2.6) while it is not differentiable in the sense $(i)$ or Definition (2.6), or

(type 2) $\tilde{f}$ is differentiable at $x_{1}$ in the sense (ii) of Definition (2.6) while it is not differentiable in the sense $(i)$ of Definition (2.6), and $\widetilde{f}$ is differentiable at $x_{2}$ in the sense (i) of Definition (2.6) while it is not differentiable in the sense (ii) or Definition (2.6). 
Proposition 2. (see (Chalco-Cano and Romn-Flores 2006)) Let $\widetilde{f}:(a, b) \rightarrow E$ and $x_{0} \in(a, b)$.

(a) If $x_{0} \in(a, b)$ is a switching point for the differentiability of $\widetilde{f}$ of type 1 , then $\widetilde{f}$ is differentiable at $x_{0}$ in the form (iv).

(b) If $x_{0} \in(a, b)$ is a switching point for the differentiability of $\widetilde{f}$ of type 2 , then $\widetilde{f}$ is differentiable at $x_{0}$ in the form (iii).

Definition 2.7. A triangular fuzzy number is defined as a fuzzy set in $E^{1}$, that is specified by an ordered triple $u=$ $(a, b, c) \in R^{3}$ with $a \leq b \leq c$ such that $u(r)=[\underline{u}(r), \bar{u}(r)]$ are the endpoints of $r$-level sets for all $r \in[0,1]$, where $\underline{u}(r)=a+(b-a) r$ and $\bar{u}(r)=c-(c-b) r$. Here, $\underline{u}(0)=$ $a, \bar{u}(0)=c, \underline{u}(1)=\bar{u}(1)=b$, which is denoted by $u(1)$. The set of triangular fuzzy numbers will be denoted by $E^{1}$.

Definition 2.8. (see (Chalco-Cano and Romn-Flores 2006)) The mapping $\tilde{f}: T \rightarrow E^{n}$ for some interval $T$ is called a fuzzy process. Therefore, its $r$-level set can be written as follows:

$$
(f(t))(r)=[f(t, r), \bar{f}(t, r)], \quad t \in T, \quad r \in[0,1] .
$$

Definition 2.9. (see (Chalco-Cano and Romn-Flores 2006)) Let $\widetilde{f}: T \rightarrow E^{n}$ be Hukuhara differentiable and denote $(f(t))(r)=[f(t, r), \bar{f}(t, r)]$. Then, the boundary function $f(t, r)$ and $\bar{f}(t, r)$ are differentiable (or Seikkala differentiable) and

$$
\left(f^{\prime}(t)\right)(r)=\left[\underline{f}^{\prime}(t, r), \bar{f}^{\prime}(t, r)\right], \quad t \in T, \quad r \in[0,1] .
$$

If $f$ is (ii)-differentiable then

$$
\left(f^{\prime}(t)\right)(r)=\left[\bar{f}^{\prime}(t, r), \underline{f}^{\prime}(t, r)\right], \quad t \in T, \quad r \in[0,1] .
$$

\section{Description of the method}

To obtain the approximation solution of Eqs.(1,2), based on Definition (2.6) we have two cases as follows:

Case (1): $\widetilde{u}(x, t)$ is $(i)$-differentiable, in this case we have,

$$
\widetilde{u}(x, t)=\widetilde{f}(x)+\int_{0}^{t}\left[\widetilde{u}(x, t)+\widetilde{u}_{x x}(x, t)\right] d t .
$$

Case (2): $\widetilde{u}(x, t)$ is (ii)-differentiable, in this case we have,

$$
\widetilde{u}(x, t)=\tilde{f}(x) \ominus(-1) \cdot \int_{0}^{t}\left[\widetilde{u}(x, t)+\widetilde{u}_{x x}(x, t)\right] d t .
$$

Now, we can write successive iterations (by using Picard method) as follows:
Case (1):

$$
\begin{aligned}
& \widetilde{u}_{0}(x, t)=\tilde{f}(x), \\
& \widetilde{u}_{n+1}(x, t)=\widetilde{f}(x)+\int_{0}^{t}\left[\widetilde{u}_{n}(x, t)+\widetilde{u}_{n_{x x}}(x, t)\right] d t, \quad n \geq 0 .
\end{aligned}
$$

Case (2):

$$
\begin{aligned}
& \tilde{u}_{0}(x, t)=\tilde{f}(x), \\
& \tilde{u}_{n+1}(x, t)=\tilde{f}(x) \ominus(-1) \cdot \int_{0}^{t}\left[\tilde{u}_{n}(x, t)+\widetilde{u}_{n_{x x}}(x, t)\right] d t, \\
& n \geq 0 .
\end{aligned}
$$

Remark 1. For $\widetilde{u}_{x x}$ we have cases as follows:

Case (1): $\widetilde{u}$ and $\widetilde{u}^{\prime}$ be (i)-differentiable and $\widetilde{u}$ and $\widetilde{u}^{\prime}$ be (ii)-differentiable

$$
\tilde{u}_{x x}(x, t)=\left[\underline{u}_{x x}(x, t, r), \bar{u}_{x x}(x, t, r)\right] .
$$

Case (2): $\widetilde{u}$ is (i)-differentiable and $\widetilde{u}^{\prime}$ is

(ii)-differentiable and $\widetilde{u}$ is (ii)-differentiable and $\widetilde{u}^{\prime}$ is

(i)-differentiable

$$
\widetilde{u}^{\prime \prime}(x, t)=\left[\bar{u}^{\prime \prime}(x, t, r), \underline{u^{\prime \prime}}(x, t, r)\right] .
$$

Remark 2. We discuss about switching points as follows:

Case (1): $\widetilde{u}$ is $(i)$-differentiable

If $\frac{\partial \underline{u}(x, t, r)}{\partial x}<0, \frac{\partial \underline{u}(x, t, r)}{\partial x}>0, x \in\left[a, x_{0}\right]$ and

$\frac{\partial \underline{u}(x, t, r)}{\partial x}>0, \frac{\partial \underline{u}(x, t, r)}{\partial x}<0, \quad x \in\left(x_{0}, b\right]$ and $r \in[0,1]$

then we have $\widetilde{u}^{\prime}(x, t)=\left[\bar{u}^{\prime}(x, t, r), \underline{u}^{\prime}(x, t, r)\right]$ and $x_{0}$ is a switching point in the form (iv).

If $\frac{\partial^{2} \underline{\underline{u}}(x, t, r)}{\partial x^{2}}<0, \frac{\partial^{2} \underline{u}(x, t, r)}{\partial x^{2}}>0, x \in\left[a, x_{1}\right]$ and

$\frac{\partial^{2} \underline{u}(x, t, r)}{\partial x^{2}}>0, \frac{\partial^{2} u(x, t, r)}{\partial x^{2}}<0, \quad x \in\left(x_{1}, b\right]$ and $r \in[0,1]$ then we have $\widetilde{u}^{\prime \prime}(x, t)=\left[\underline{u}^{\prime \prime}(x, t, r), \bar{u}^{\prime \prime}(x, t, r)\right]$ and $x_{1}$ is a switching point in the form (iv).

Case (2): $\widetilde{u}$ is (ii)-differentiable

If $\frac{\partial \underline{u}(x, t, r)}{\partial x}>0, \frac{\partial \underline{u}(x, t, r)}{\partial x}<0, x \in\left[a, x_{0}\right]$ and

$\frac{\partial \underline{u}(x, t, r)}{\partial x}<0, \frac{\partial \underline{u}(x, t, r)}{\partial x}>0, \quad x \in\left(x_{0}, b\right]$ and $r \in[0,1]$

then we have $\widetilde{u}^{\prime}(x, t)=\left[\underline{u}^{\prime}(x, t, r), \bar{u}^{\prime}(x, t, r)\right]$ and $x_{0}$ is a switching point in the form (iii).

If $\frac{\partial^{2} \underline{u}(x, t, r)}{\partial x^{2}}>0, \frac{\partial^{2} \underline{u}(x, t, r)}{\partial x^{2}}<0, x \in\left[a, x_{1}\right]$ and $\frac{\partial^{2} \underline{u}(x, t, r)}{\partial x^{2}}<0, \frac{\partial^{2} u(x, t, r)}{\partial x^{2}}>0, \quad x \in\left(x_{1}, b\right]$ and $r \in[0,1]$ then we have $\widetilde{u}^{\prime \prime}(x, t)=\left[\bar{u}^{\prime \prime}(x, t, r), \underline{u}^{\prime \prime}(x, t, r)\right]$ and $x_{1}$ is a switching point in the form (iii).

Case (3): $\widetilde{u}$ is $(i)$-differentiable

If $\frac{\partial \underline{u}(x, t, r)}{\partial x}<0, \frac{\partial \underline{u}(x, t, r)}{\partial x}>0, \forall x \in[a, b]$ then we have

$\widetilde{u}^{\prime}(x, t)=\left[\underline{u}^{\prime}(x, t, r), \bar{u}^{\prime}(x, t, r)\right]$.

If $\frac{\partial^{2} \underline{u}(x, t, r)}{\partial x^{2}}<0, \frac{\partial^{2} \underline{u}(x, t, r)}{\partial x^{2}}>0, x \in\left[a, x_{0}\right]$ and

$\frac{\partial^{2} \underline{u}(x, t, r)}{\partial x^{2}}>0, \frac{\partial^{2} \underline{u}(x, t, r)}{\partial x^{2}}<0, \quad x \in\left(x_{0}, b\right]$ and $r \in[0,1]$ 
then we have $\widetilde{u}^{\prime \prime}(x, t)=\left[\bar{u}^{\prime \prime}(x, t, r), \underline{u}^{\prime \prime}(x, t, r)\right]$ and $x_{0}$ is a switching point in the form (iv).

Case (4): $\tilde{u}$ is (ii)-differentiable

If $\frac{\partial \underline{u}(x, t, r)}{\partial x}>0, \frac{\partial \underline{u}(x, t, r)}{\partial x}<0, \forall x \in[a, b]$ then we have

$\tilde{u}^{\prime}(x, t)=\left[\bar{u}^{\prime}(x, t, r), \underline{u}^{\prime}(x, t, r)\right]$.

If $\frac{\partial^{2} \underline{u}(x, t, r)}{\partial x^{2}}>0, \frac{\partial^{2} \underline{u}(x, t, r)}{\partial x^{2}}<0, x \in\left[a, x_{1}\right]$ and

$\frac{\partial^{2} \underline{u}(x, t, r)}{\partial x^{2}}<0, \frac{\partial^{2} \underline{u}(x, t, r)}{\partial x^{2}}>0, \quad x \in\left(x_{1}, b\right]$ and $r \in[0,1]$ then we have $\widetilde{u}^{\prime \prime}(x, t)=\left[\underline{u}^{\prime \prime}(x, t, r), \bar{u}^{\prime \prime}(x, t, r)\right]$ and $x_{1}$ is a switching point in the form (iii).

\section{Existence and convergence analysis}

In this section we are going to prove the existence and uniqueness of the solution and convergence of the method by using the following assumptions.

Consider $\tilde{f}(x)$ is bounded for all $x \in[a, b]$ and

$$
D\left(\tilde{u}_{x x}(x, t), \tilde{u}_{x x}^{*}(x, t)\right) \leq L D\left(\widetilde{u}(x, t), \tilde{u}^{*}(x, t)\right), \quad L>0 .
$$

Let,

$$
\alpha=(T+T L) .
$$

Lemma 1. If $\widetilde{u}, \widetilde{v}, \widetilde{w} \in E^{n}$ and $\lambda \in R$, then,

(i) $D(\widetilde{u} \ominus \widetilde{v}, \widetilde{u} \ominus \widetilde{w})=D(\widetilde{v}, \widetilde{w})$,

(ii) $D(\ominus \lambda \widetilde{u}, \ominus \lambda \widetilde{v})=|\lambda| D(\widetilde{u}, \widetilde{v})$.

Proof (i). By the definition of $D$, we have,

$$
\begin{aligned}
& D(\widetilde{u} \ominus \widetilde{v}, \tilde{u} \ominus \widetilde{w}) \\
& =\max \left\{\sup _{r \in[0,1]}|\underline{u(r)-v(r)}-\underline{u(r)-w(r)}|,\right. \\
& \left.\sup _{r \in[0,1]}|\overline{u(r)-v(r)}-\overline{u(r)-w(r)}|\right\} \\
& =\max \left\{\sup _{r \in[0,1]} \mid(\underline{u}(r)-\underline{v}(r))-(\underline{u}(r)-\underline{w}(r) \mid \text {, }\right. \\
& \left.\sup _{r \in[0,1]}|(\bar{u}(r)-\bar{v}(r))-(\bar{u}(r)-\bar{w}(r))|\right\} \\
& =\max \left\{\sup _{r \in[0,1]}|\underline{w}(r)-\underline{v}(r)|, \sup _{r \in[0,1]}|\bar{w}(r)-\bar{v}(r)|\right\} \\
& =\max \left\{\sup _{r \in[0,1]}|\underline{v}(r)-\underline{w}(r)|, \sup _{r \in[0,1]}|\bar{v}(r)-\bar{w}(r)|\right\} \\
& =D(\widetilde{v}, \widetilde{w}) \text {. }
\end{aligned}
$$

\begin{tabular}{|c|c|c|}
\hline$x$ & $(\underline{u}, r=0.1, n=25, t=0.6)$ & $(\bar{u}, r=0.1, n=25, t=0.6)$ \\
\hline-0.2 & 0.34245 & 0.68532 \\
\hline-0.1 & 0.35571 & 0.67259 \\
\hline 0.0 & 0.36438 & 0.66135 \\
\hline 0.1 & 0.35724 & 0.67056 \\
\hline 0.2 & 0.34862 & 0.67843 \\
\hline 0.3 & 0.33597 & 0.68453 \\
\hline 0.4 & 0.32551 & 0.69064 \\
\hline
\end{tabular}

\section{Proof (ii):}

$$
\begin{aligned}
& D(\ominus \lambda \widetilde{u}, \ominus \lambda \widetilde{v}) \\
& =\max \left\{\sup _{r \in[0,1]}\left|\frac{\lambda u(r)}{|\overline{\lambda v(r)}|}\right|,\right. \\
& \left.\left.\quad \sup _{r \in[0,1]}\right] \overline{\overline{\lambda u(r)}}-\overline{\lambda v(r)} \mid\right\} \\
& =\max \left\{\sup _{r \in[0,1]}|\underline{\lambda u(r)}-\overline{\lambda v(r)}|,\right. \\
& \left.\quad \sup _{r \in[0,1]}|\overline{\overline{\lambda u(r)}}-\overline{\overline{\lambda v(r)}}|\right\} \\
& =D(\lambda \widetilde{u}, \lambda \widetilde{v})=|\lambda| D(\widetilde{u}, \widetilde{v}) .
\end{aligned}
$$

Table 1 Numerical results for Example 5.1

Theorem 1. Let $0<\alpha<1$, then Eqs.(1,2), have

\begin{tabular}{|c|c|c|}
\hline$x$ & $(\underline{u}, r=0.2, n=17, t=0.7)$ & $(\bar{v}, r=0.2, n=17, t=0.7)$ \\
\hline 0.1 & 0.3726508 & 0.7023467 \\
\hline 0.2 & 0.3827526 & 0.6939411 \\
\hline 0.3 & 0.3957162 & 0.6848745 \\
\hline 0.4 & 0.4136805 & 0.6612719 \\
\hline 0.5 & 0.4372286 & 0.6559328 \\
\hline 0.6 & 0.4438574 & 0.6337306 \\
\hline
\end{tabular}
an unique solution and the solution $\widetilde{u}_{n}(x, t)$ obtained from the relation (8) using Picard method converges to the exact solution of the problems $(1,2)$ when $\widetilde{u}$ is (ii)differentiable.

Proof. Let $\widetilde{u}$ and $\widetilde{u}^{*}$ be two different solutions of Eqs. $(1,2)$ then

$$
\begin{aligned}
& D\left(\widetilde{u}(x, t), \widetilde{u}^{*}(x, t)\right) \\
& =D \tilde{f}(x) \ominus(-1) \cdot \int_{0}^{t}\left[\tilde{u}(x, t)+\widetilde{u}_{x x}(x, t)\right] d t, \\
& \left.\tilde{f}(x) \ominus(-1) \cdot \int_{0}^{t}\left[\widetilde{u}^{*}(x, t)+\widetilde{u}_{x x}^{*}(x, t)\right] d t\right) \\
& =D\left(\ominus(-1) \cdot \int_{0}^{t}\left[\widetilde{u}(x, t)+\widetilde{u}_{x x}(x, t)\right] d t,\right. \\
& \left.\ominus(-1) \cdot \int_{0}^{t}\left[\widetilde{u}^{*}(x, t)+\widetilde{u}_{x x}^{*}(x, t)\right] d t\right) \\
& \leq T\left(D\left(\widetilde{u}(x, t), \widetilde{u}^{*}(x, t)\right)\right)+T L\left(D\left(\widetilde{u}(x, t), \widetilde{u}^{*}(x, t)\right)\right) \\
& =\alpha D\left(\widetilde{u}(x, t), \widetilde{u}^{*}(x, t)\right) \text {. }
\end{aligned}
$$

From which we get $(1-\alpha) D\left(\widetilde{u}(x, t), \widetilde{u}^{*}(x, t)\right) \leq 0$. Since $0<\alpha<1$, then $D\left(\widetilde{u}(x, t), \widetilde{u}^{*}(x, t)\right)=0$. Implies $\widetilde{u}(x, t)=$ $\widetilde{u}^{*}(x, t)$.

Also, we have

$$
D\left(\widetilde{u}_{n+1}(x, t), \tilde{u}(x, t)\right) \leq \alpha D\left(\widetilde{u}_{n}, \widetilde{u}\right) .
$$

Since, $0<\alpha<1$, then $D\left(\widetilde{u}_{n}(x, t), \widetilde{u}(x, t)\right) \rightarrow 0$ as $n \rightarrow \infty$. Therefore, $\widetilde{u}_{n}(x, t) \rightarrow \widetilde{u}(x, t)$.

\section{Table 2 Numerical results for Example 5.2}


Table 3 Numerical results for Example 5.2

\begin{tabular}{|c|c|c|}
\hline$x$ & $(\underline{u}, r=0.2, n=21, t=0.7)$ & $(\bar{v}, r=0.2, n=21, t=0.7)$ \\
\hline 0.1 & 0.4646316 & 0.7954225 \\
\hline 0.2 & 0.4717726 & 0.7844835 \\
\hline 0.3 & 0.4823549 & 0.7737607 \\
\hline 0.4 & 0.5074658 & 0.7528153 \\
\hline 0.5 & 0.5263437 & 0.7474326 \\
\hline 0.6 & 0.5309183 & 0.7215178 \\
\hline
\end{tabular}

Remark 3. The proof of other case is similar to the previous theorems.

\section{Numerical examples}

In this section, we solve the Cauchy reaction-diffusion equation by using the Picard method. The program has been provided with Mathematica 6 according to the following algorithm where $\varepsilon$ is a given positive value.

\section{Algorithm :}

Step 1. Set $n \leftarrow 0$.

Step 2. Calculate the recursive relations (7) or (8).

Step 3. If $D\left(\widetilde{u}_{n+1}(x, t), \tilde{u}_{n}(x, t)\right)<\varepsilon$ then go to step 4 , else $n \leftarrow n+1$ and go to step 2 .

Step 4. Print $\tilde{u}_{n}(x, t)$ as the approximate of the exact solution.

Example 5.1. Consider the Cauchy reaction-diffusion equation as follows:

$$
\tilde{u}_{t}(x, t)=\widetilde{u}_{x x}(x, t)+\widetilde{u}(x, t) .
$$

With initial condition:

$$
\tilde{u}(x, 0)=\tilde{f}(x)=\left((1-r) x^{3},(r-1) x^{3}\right) .
$$

$\epsilon=10^{-4} \cdot x=0$ is a switching point.

Case (1): $n=22$ and $\alpha=0.8652$.

Case (2): $\alpha=0.84569$.

Table 1 shows that, the approximation solution of the Cauchy reaction-diffusion equation is convergent with 25 iterations by using the Picard method when $\widetilde{u}$ is (ii)-differentiable.

Example 5.2. Consider the Cauchy reaction-diffusion equation as follows:

$$
\tilde{u}_{t}(x, t)=\widetilde{u}_{x x}(x, t)+\widetilde{u}(x, t) .
$$

With initial condition:

$$
\begin{aligned}
& \tilde{u}(x, 0)=\tilde{f}(x)=\left(x^{2}+1, x^{2}+2, x^{2}+3\right) . \\
\epsilon= & 10^{-3} .
\end{aligned}
$$

Case (1): $\alpha=0.7546$.

Table 2 shows that, the approximation solution of the Cauchy reaction-diffusion equation is convergent with 17 iterations by using the Picard method when $\tilde{u}$ is (i)-differentiable.

Case (2): $\alpha=0.7762$.

Table 3 shows that, the approximation solution of the Cauchy reaction-diffusion equation is convergent with 21 iterations by using the Picard method when $\tilde{u}$ is (ii)-differentiable.

\section{Conclusion}

The Picard method has been shown to solve effectively, easily and accurately a large class of nonlinear problems with the approximations which convergent are rapidly to exact solutions. In this work, the Picard method has been successfully employed to obtain the approximate solution of the Cauchy reaction-diffusion equation under generalized $H$-differentiability.

Received: 21 July 2012 Accepted: 27 September 2012

Published: 13 March 2013

\section{References}

Abbasbandy S, Allahviranloo T (2000) Numerical solutions of fuzzy differential equations by Taylor method. J Comput Meth Appl Math 2: 113-124

Abbasbandy S, Allahviranloo T, Lopez-Pouso O, Nieto J. J. (2004) Numerical methods for fuzzy differential inclusions. Comput Math Appl 48: 1633-1641

Abbasbandy S, Nieto J. J., Alavi M (2005) Tuning of reachable set in one dimensional fuzzy differential inclusions. Chaos Soliton Fractals 26: 1337

Abbod MF, Von Keyserlingk DG, Linkens DA, Mahfouf M (2001) Survey of utilisation of fuzzy technology in medicine and healthcare. Fuzzy Sets Syst 120: 331-349

Afshar Kermani M, Saburi F (2007) Numerical method for fuzzy partial differential equations. Appl Math Sci 1: 1299-1309

Allahviranloo T (2002) Difference methods for fuzzy partial differential equations. Comput Methods Appl Math 2: 233-242

Allahviramloo T (2005) The Adomian decomposition method for fuzzy system of linear equations. Appl Mathematics and Comput 163: 553-563

Allahviranloo T, Ahmady N, Ahmady E (2007) Numerical solution of fuzzy differential equations by predictorÜcorrector method. Inform Sci 177: 1633-1647

Barkhordari Ahmadi M, Kiani NA (2011) Solving fuzzy partial differential equation by differential transformation method. J Appl Math 7: 1-16

Barro S, Marin R (2002) Fuzzy logic in medicine. Physica-Verlag, Heidelberg

Bede B (2008) Note on Numerical solutions of fuzzy differential equations by predictor-corrector method. Inform Sci 178: 1917-1922

Bede B, Gal SG (2005) Generalizations of the differentiability of fuzzy number valued functions with applications to fuzzy differential equation. Fuzzy Set Syst 151: 581-599

Bede B, Imre J, Rudas C, Attila L (2007) First order linear fuzzy differential equations under generalized differentiability. Inform Sci 177: 3627-3635

Buckley JJ, Feuring T (1999) Introduction to fuzzy partial diferential equations. Fuzzy Sets and Syst 105: 241-248

Buckley, JJ, Feuring, T (2000) Fuzzy differential equations. Fuzzy Set Syst 110 : 43-54

Buckley JJ, Jowers LJ (2006) Simulating Continuous Fuzzy Systems. Springer-Verlag, Berl, Heidelberg

Buckley JJ, Feuring T, Hayashi Y (2002) Linear systems of first order ordinary differential equations: fuzzy initial conditions. Soft Comput 6: 415-421

Chalco-Cano Y, Román-Flores H (2006) On new solutions of fuzzy differential equations. Chaos Soliton Fractals: 1016-1043

Chalco-Cano Y, Román-Flores H, Rojas-Medar MA, Saavedra O, Jimnez-Gamero M (2007) The extension principle and a decomposition of fuzzy sets. Inform Sci 177: 5394-5403

Chalco-Cano Y, Roman-Flores H, Jimnez-Gamero MD (2011) Generalized derivative and $\pi$-derivative for set-valued functions. Inf Sci 181: 2177-2188 
Chapko R, Johansson BT (2012) On the numerical solution of a Cauchy problem for the Laplace equation via a direct integral equation approach. Inverse Problems and Imaging 6: 25-38

Chen CK, Ho SH (1999) Solving partial differential equations by two-dimensional differential transform method. Appl Math Comput 106: $171-179$

Chen Y-Y, Chang Y-T, Chen B-S (2009) Fuzzy solutions to partial differential equations: adaptive approach. IEEE Trans on Fuzzy Syst 17: 116-127

Cho YJ, Lan HY (2007) The existence of solutions for the nonlinear first order fuzzy differential equations with discontinuous conditions. Dyn Contin Discrete 14: 873-884

Congxin W, Shiji S (1993) Exitance theorem to the Cauchy problem of fuzzy differential equations under compactance-type conditions. Inform Sci 108: $123-134$

Datta DP (2003) The golden mean, scale free extension of real number system, fuzzy sets and $1 / f$ spectrum in physics and biology. Chaos, Solitons and Fractals 17: 781-788

Diamond P (1999) Time-dependent differential inclusions, cocycle attractors and fuzzy differential equations. IEEE Trans Fuzzy Syst 7: 734-740

Diamond, P (2002) Brief note on the variation of constants formula for fuzzy differential equations. Fuzzy Set Syst 129: 65-71

Ding Z, Ma M, Kandel A (1997) Existence of solutions of fuzzy differential equations with parameters. Inform Sci 99: 205-217

Dubois D, Prade H (1980) Theory and application, fuzzy sets and systems. Academic Press

Dubois, D, Prade H (1982) Towards fuzzy differential calculus: Part 3, differentiation. Fuzzy Set Syst 8: 225-233

Dou FF, Hon YC (2012). Kernel-based approximation for Cauchy problem of the time-fractional diffusion equation 36: 1344-1352

El Naschie MS (2005) From experimental quantum optics to quantum gavity via a fuzzy Kahler manifold. Chaos, Solitons and Fractals 25: 969-977

Farajzadeh A, Hossein Pour A, Amini M (2010) An Explicit Method for Solving Fuzzy Partial Differential Equation. Int Math Forum 5: 1025-1036

Fard OS (2009) A numerical scheme for fuzzy cauchy problems. J Uncertain Syst 3: 307-314

Fard O. S. (2009) An iterative scheme for the solution of generalized system of linear fuzzy differential equations. World Appl Sci J 7: 1597-1604

Fard OS, Kamyad AV (2011) Modified k-step method for solving fuzzy initial value problems. Iran J Fuzzy Syst 8(3): 49-63

Fard OS, Hadi Z, Ghal-Eh N, Borzabadi AH (2009) A note on iterative method for solving fuzzy initial value problems. J Adv Res Sci Comput 1: 22-33

Fard OS, Bidgoli TA, Borzabadi AH (2010) Approximate-analytical approach to nonlinear FDEs under generalized differentiability. J Adv Res Dyn Control Syst 2: 56-74

Fei W (2007) Existence and uniqueness of solution for fuzzy random differential equations with non-Lipschitz coefficients. Inform Sci 177: 329-4337

Feng G, Chen G (2005) Adaptative control of discrete-time chaotic system: a fuzzy control approach. Chaos, Solitons and Fractals 23: 459-467

Goetschel R, Voxman W (1986) Elementary calculus. Fuzzy Sets Syst 18: $31-43$

Guo M, Xue X, Li R (2003) Impulsive functional differential inclusions and fuzzy population models. Fuzzy Sets Syst 138: 601-615

Jang MJ, Chen CL, Liy YC (2000) On solving the initial-value problems using the differential transformation method. Appl Math Comput 115: $145-160$

Jiang W, Guo-Dong Q, Bin D, $H_{\infty}$ variable univerese adaptative fuzzy control for chaotic systems (2005). Chaos, Solitons and Fractals 24: 1075-1086

Jowers LJ, Buckley JJ, Reilly KD (2007) Simulating continuous fuzzy systems. Inform Sci 177: 436-448

Kaleva O (1987) Fuzzy differential equations. Fuzzy Set Syst 24: 301-317

Kaleva, O (1990) The Cauchy problem for fuzzy differential equations. Fuzzy Set Syst 35: 389-396

Kaleva, O (2006) A note on fuzzy differential equations. Nonlinear Anal 64 895-900

Kauffman A, Gupta MM (1991) Introduction to Fuzzy Arithmetic:Theory and Application. Van Nostrand Reinhold, New York

Lopez RR (2008) Comparison results for fuzzy differential equations. Inform Sci 178: 1756-1779

Ma M, Friedman M, Kandel A (1999) Numerical solutions of fuzzy differential equations. Fuzzy Set Syst 105: 133-138
Mizukoshi MT, Barros LC, Chalco-Cano Y, Román-Flores H, Bassanezi RC (2007) Fuzzy differential equations and the extension principle. Inform Sci 177: 3627-3635

Moghadam MM, Jalal I (2011) Finite Volume Methods for Fuzzy Parabolic Equations. J Math Comput Sci 2: 546-558

Nguyen HT (1978) A note on the extension principle for fuzzy sets. J Math Anal Appl 64: 369-380

Oberguggenberger M, Pittschmann S (1999) Differential equations with fuzzy parameters. Math Mod Syst 5: 181-202

Papaschinopoulos G, Stefanidou G, Efraimidi P (2007) Existence uniqueness and asymptotic behavior of the solutions of a fuzzy differential equation with piecewise constant argument. Inform Sci 177: 3855-3870

Puri ML, Ralescu DA (1983) Differentials of fuzzy functions. J Math Anal Appl 91: $552-558$

Puri ML, Ralescu D (1986) Fuzzy random variables. J Math Anal Appl 114: 409-422

Seikkala S (1987) On the fuzzy initial value problem. Fuzzy Set Syst 24: 319-330

Solaymani Fard O, Ghal-Eh N (2011) Numerical solutions for linear system of first-order fuzzy differential equations with fuzzy constant coefficients. Infor Sci 181: 4765-4779

Song S, Guo L, Feng C (2000) Global existence of solutions to fuzzy differential equations. Fuzzy Set Syst 115: 371-376

Rouhparvar H, Abbasbandy S, Allahviranloo T (2010) Existence and uniqueness of solution of an uncertain characteristic cauchy reaction-diffusion equation by Adomian decomposition method. Math Comput Appl 15: 404-419

Verma P, Sing P, George KV, Singh HV, Devotta S, Singh RN (2009) Uncertainty analysis of transport of water and pesticide in an unsaturated layered soil profile using fuzzy set theory. Appl Math Modelling 33: 770-782

Zadeh LA (1965). Fuzzy Sets. Inf and Control 8: 338-353

Zimmermann (1991) Fuzzy sets theory and its applications. Kluwer Academic Press, Dordrecht

doi:10.1186/2193-1801-2-108

Cite this article as: Sadigh Behzadi: Solving Cauchy reaction-diffusion equation by using Picard method. SpringerPlus 2013 2:108

\section{Submit your manuscript to a SpringerOpen ${ }^{\circ}$ journal and benefit from:}

Convenient online submission

- Rigorous peer review

- Immediate publication on acceptance

- Open access: articles freely available online

- High visibility within the field

- Retaining the copyright to your article

Submit your next manuscript at springeropen.com 